\title{
DOGMATISMOS INTERPELADOS POR GÊNERO E RAÇA: RUMO A UMA ESPIRITUALIDADE DA ALTERIDADE
}

\author{
Tânia Mara Vieira Sampaio*
}

\section{RESUMO}

A concepção das relações sociais de gênero e sua interseccionalidade com outros marcadores sociais como raça, classe, território, idade, escolarização, heterossexualidade, homossexualidade entre outros traçará o percurso da desconstrução de verdades dogmáticas no campo da religião. Desse modo, apresentará caminhos epistemológicos para pensar uma espiritualidade da gratuidade, por meio do enfrentamento das discriminações e subordinações no âmbito das relações sociais de poder. O encontro relacional em que o eu e @ outr@ se implicam e se interpelam mutuamente @s responsabiliza a viverem uma experiência ética de alteridade.

Palavras Chave: Gênero. Interseccionalidade. Poder. Alteridade. Espiritualidade

\section{THE DOGMATISM INTERPELLED BY GENDER AND RACE: TOWARDS A SPIRITUALITY OF OTHERNESS}

\section{ABSTRACT}

The conception of social gender relations and their intersectionality with other social markers such as race, class, territory, age, education, heterosexuality, homosexuality, among others, will trace the path of deconstruction of dogmatic truths in the field of religion. In this way, it will present epistemological ways to think about a spirituality of gratuity, through the confrontation of discrimination and subordination in the context of social power relations. The relational encounter in which the self and the other are involved and mutually question each other makes them responsible for living an ethical experience of otherness.

Keywords: Gender. Intersectionality. Power. Otherness. Spirituality.

* Doutora e mestre em Ciências da Religião pela UMESP, pós-doutorado em estudos do lazer pela UFMG. Docente em regime de dedicação exclusiva no Instituto Federal de Goiás - IFG Campus Luziânia-GO 


\section{EL DOGMATISMO INTERPELADO POR EL GÉNERO Y LA RAZA: HACIA UNA ESPIRITUALIDAD DE LA ALTERIDAD}

\section{RESUMEN}

La concepción de las relaciones sociales de género y su interseccionalidad con otros marcadores sociales como raza, clase, territorio, edad, educación, heterosexualidad, homosexualidad, entre otros, marcará el camino de la deconstrucción de las verdades dogmáticas en el campo de la religión. De esta manera, presentará formas epistemológicas de pensar una espiritualidad de la gratuidad, a través del enfrentamiento de la discriminación y la subordinación en el contexto de las relaciones sociales de poder. El encuentro relacional en el que el yo y el otro se involucran y se cuestionan mutuamente los hace responsables de vivir una experiencia ética de la alteridad.

Palabras clave: Género. Interseccionalidad. Poder. Alteridad. Espiritualidad.

\section{Da calma e do Silêncio}

Quando eu morder

a palavra,

por favor,

não me apressem,

quero mascar,

rasgar entre os dentes,

a pele, os ossos, o tutano

do verbo,

para assim versejar

o âmago das coisas.

Quando meu olhar

se perder no nada,

por favor,

não me despertem,

quero reter,

no adentro da íris,

a menor sombra,

do ínfimo movimento.
Quando meus pés

abrandarem na marcha,

por favor,

não me forcem.

Caminhar para quê?

Deixem-me quedar, deixem-me quieta, na aparente inércia.

Nem todo viandante anda estradas, há mundos submersos, que só o silêncio da poesia penetra.

Conceição Evaristo ${ }^{1}$
Conceição Evaristo, no livro Poemas da recordação e outros movimentos. Belo Horizonte: Nandyala, 2008 (p. 123, 124). 
Na companhia de Conceição Evaristo desejo iniciar o percurso dessa reflexão. A beleza dos pequenos detalhes do cotidiano e a captura dos sentidos de vida anunciam que é possível acreditar em novos horizontes para as relações humanas e para sua produção de conhecimentos. Não sem dificuldades, somos instadas a repensar o que fazemos de nossas vidas e de nosso trabalho diário. Os saberes e sabores que constituem nossa lida em qualquer área do conhecimento amparam a possibilidade de dizer que as relações sociais de poder marcadas pelo gênero e pela raça não são fruto de uma essência dada, e sim inventada, promovendo uma "naturalidade" aparente, que esconde uma construção histórico-cultural e naturalizada inadvertidamente. Todo esse processo gera normatividades dogmáticas e, por isso, parecem intocáveis; mas Ivone Gebara (1997) há muito tempo abriu uma brecha em meu olhar quando afirmou que contra os dogmatismos, que venha o movimento da vida!

Por isso, aceito com você, que ora lê, o convite a um compromisso do sonho e da indignação coletiva, assumindo simultaneamente a crítica à realidade, a afirmação da esperança e da reinvenção das relações, de modo que a discriminação, a hierarquização e a exclusão não sejam as regras do jogo cotidiano das pessoas, mas que nossos sonhos de justiça e paz, instaurem a beleza lúdica da roda da conversa capaz de reinventar as relações marcadas pelo desrespeito ao direito às diferenças, o qual as transforma em assimetrias sociais.

Para ir ao encontro desse compromisso da reinvenção das relações, me acerco da dimensão da interseccionalidade de gênero, raça e classe, na qualidade de prismas ou de categorias de análise das relações sociais de poder que promovem ou não a justiça social. Considerando que somos seres em constantes movimentos relacionais e nos apresentamos para a relaçãocom @ Outr@, a outra pessoa,com os demais seres vivos e com o ecossistema, identificando-nos por nosso sexo, nossa raça, nosso gênero, nossa etnia, nossa orientação sexual, nossa classe social, nossa idade, nossas crenças etc., é que proponho a reflexão de Judith Butler sobre essa relação.

O corpo implica mortalidade, vulnerabilidade, agência: a pele e a carne expõem-nos ao olhar dos outros, mas também ao toque, e à violência, e os corpos põem-nos em risco de se tornarem a agência 
e o instrumento de tudo isto também. Embora lutemos por direitos sobre os nossos próprios corpos, os próprios corpos pelos quais lutamos não são apenas nossos. O corpo tem a sua dimensão invariavelmente pública. Constituído como um fenómeno social na esfera pública, o meu corpo é e não é meu. Dado desde o início ao mundo dos outros, carrega a sua marca, é formado dentro do cadinho da vida social; só mais tarde, e com alguma incerteza, reivindico o meu corpo como meu, se é que de facto alguma vez o faço (Judith BUTLER, 2018, p. 28).

Refletir sobre gênero e raça provoca e evoca em nós diversas imagens, mas destaco a das lutas das mulheres, da população negra e indígena e de outros grupos sociais, organizados em movimentos feministas, em movimentos negros, em movimentos indígenas, em movimentos LGBTQIA+ e em múltiplas outras organizações que foram mudando a história do acesso das mulheres, da raça negra, das populações indígenas, das pessoas em situação de vulnerabilidade, dos movimentos pela pluralidade de gênero e contra a heteronormatividade na sociedade. Por isso, nas palavras de Conceição Evaristo reitero o apelo: "quando meu olhar se perder no nada, por favor, não me despertem, quero reter, no adentro da íris, a menor sombra, do ínfimo movimento" (2008, p.123). Meus olhos querem acompanhar os muitos movimentos em busca pelo respeito aos direitos de ser no mundo com dignidade, independente dos marcadores sociais por meio dos quais se pretende controlar a nossa corporeidade, partindo de um modelo único e universal.

Os debates epistemológicos já derrubaram a hegemonia das verdades absolutas, das certezas deterministas, dos universais que tomaram o homem (branco, ocidental, cristão, androcêntrico, masculino, heterossexual, patriarcal, enriquecido) como padrão de humanidade. Das ciências sociais e humanas às ciências exatas e da natureza, esses paradigmas já foram abalados em sua estrutura e alicerce, cabe a nós realizar processos de des-instalação, de derrubada dessas "vigas mestres". Estamos, como disse Ilya Prigogine (1996), em tempo de "avançar sobre possibilidades", estamos diante do conhecimento em um tempo em que não se pode mais afirmar certezas ou leis deterministas. Segundo ele, a complexidade do mundo real requer "uma ciência que permite que se viva a criatividade humana como a expressão singular 
de um traço fundamental comum a todos os níveis da natureza" (Ilya PRIGOGINE, 1996, p.14).

A interseccionalidade de gênero e raça com outros marcadores sociais e a des-construção das verdades dogmáticas serão os eixos epistemológicos para pensar a espiritualidade como uma das possibilidades de aproximação da temática da religião. Caminho na busca do encontro relacional em que o eu e @ outr@ se implicam e se interpelam mutuamente exigindo a experiência ética da alteridade, como apontou Emmanuel Lévinas (1988).

\section{GÊNERO, INTERSECCIONALIDADE E RELAÇÕES SOCIAIS DE PODER}

A concepção das relações sociais de gênero e sua interseccionalidade apresenta-se como um paradigma, capaz não simplesmente de visibilizar mulheres e/ou grupos oprimidos, mas de iluminar as descobertas sobre a estruturação das opressões e dos jogos de poder que organizam discursos normativos e estabelecem controles sociais, inclusive na produção dos saberes. Isto porque a categoria gênero tem potencial para identificar as assimetrias ou desigualdades entre homens e mulheres, mulheres e mulheres, homens e homens, expressas em processos discriminatórios e de subordinação que denotam que as desigualdades entre esses grupos sociais tende a aumentar e complexificar-se quando interseccionada com classe social, raça, etnia, hetero e homossexualidade e outros marcadores sociais.

As desigualdades eram e ainda são justificadas, não raras vezes, por setores conservadores científicos, políticos e religiosos, com base na diferença biológica entre homens e mulheres, entre brancos e negros, entre seres humanos e natureza. Em contraposição a isto, a categoria analítica gênero contribuiu para esclarecer aspectos fundamentais, entre os quais, a compreensão de que as distinções biológicas são também fruto de construções sociais e culturais. Estas criam uma padronização para conceber o feminino e o masculino como se fossem atributos, com origem na essência humana, quando em verdade são construções culturais que fixam padrões de feminilidade e masculinidade normativos, gerando processos em que as distintas experiências humanas não cabem. Nessa descoberta, de que a análise de gênero interdependente 
da interseccionalidade era capaz de provocar desconstruções dogmáticas, foi que desejei, com Conceição Evaristo, que "quando eu morder a palavra, por favor, não me apressem, quero mascar, rasgar entre os dentes, a pele, os ossos, o tutano do verbo, para assim versejar o âmago das coisas" (2008, p.123).

Ao "morder a palavra" os aspectos relacionais e culturais foram emergindo como elementos estruturantes das construções sociais do gênero, possibilitando avançar na superação da dualidade biológica e perceber a multiplicidade de masculinidades e feminilidades possíveis na construção identitária. Ou, nas palavras de Judith Butler, "como um modo de relação, nem o gênero, nem a sexualidade são exatamente uma possessão, mas sim um modo de ser desapossado, um modo de ser para outro ou em virtude de outro" (Judith BUTLER, 2018, p. 26).

Os estudos sobre as masculinidades e feminilidades possíveis corroboram que não há um biológico que não seja culturalizado, bem como o inverso, conforme o confirma a posição de Edgard Morin, “o ser humano nos é revelado em sua complexidade: ser, ao mesmo tempo, totalmente biológico e totalmente cultural" (2000, p.40). Guacira Louro (1997), por sua vez, ao debater as múltiplas masculinidades e feminilidades em relações sociais, e estas adensadas pelas condições de raça, de etnia, de classe, de idade que marcam a corporeidade, nos provoca a olhar para a pluralidade do modo de ser e estar no mundo de cada pessoa e nas relações que se estabelecem.

Considerando que ademais da importância de as relações sociais de gênero ocuparem um espaço significativo na reflexão sobre as desigualdades, não é possível esquecer dos trabalhos de Stuart Hall (2006, p.12-13) que, ao analisar a constituição identitária, afirma que "a identidade torna-se uma 'celebração móvel': formada e transformada continuamente em relação às formas pelas quais somos representad@s ou interpelad@s nos sistemas culturais que nos rodeiam. É definida historicamente e não biologicamente". Assim como "a questão não é simplesmente que visto que nossas diferenças raciais não nos constituem inteiramente, somos sempre diferentes e estamos sempre negociando diferentes tipos de diferenças - de gênero, sexualidade e de classe" (HALL, 2003, p. 346). 
Nesse sentido, caminha a convicção de que a interseccionalidade, juntamente com gênero, é fundamental para assumir a interação de marcadores identitários que nos permitam sair da mulher branca universal ou do negro genérico. Isto porque as garras do racismo, do sexismo, do patriarcalismo na estrutura capitalista, se manifestam de modo que as subordinações não sejam as mesmas para mulheres brancas e mulheres negras, como também não seja a mesma para a mulher negra em relação ao homem negro. A confluência desses pertencimentos de nossa corporeidade exige que a análise de gênero não se reduza ao tratamento das lutas ou questões das mulheres, mas identifique os grupos sociais mulheres brancas, negras, indígenas, e nestes grupos sociais se pergunte pelas condições de classe, de geração, de acesso ao ensino formal e/ ou universitário, entre tantas outras intersecções, pois a análise precisa assumir que estas variáveis sociais não são independentes, mas se constituem. Nos estudos de Kimberlé Crenshaw é possível perceber as diversas estruturas de poder que promovem a discriminação advindos da interconexão desses marcadores sociais.

Considerando que a discriminação racial é frequentemente marcada pelo gênero, pois as mulheres podem às vezes vivenciar discriminações e outros abusos dos direitos humanos de uma maneira diferente dos homens, o imperativo de incorporação do gênero põe em destaque as formas pelas quais homens e mulheres são diferentemente afetados pela discriminação racial e por outras intolerâncias correlatas. Portanto, a incorporação do gênero, no contexto da análise do racismo, não apenas traz à tona a discriminação racial contra as mulheres, mas também permite um entendimento mais profundo das formas específicas pelas quais o gênero configura a discriminação também enfrentada pelos homens (Kimberlé CRENSHAW, 2002, p.173)

Desde um marco histórico, nesse debate de gênero, com a publicação da concepção de Joan Scott (1995) no Brasil no início dos anos noventa - e difundida nos estudos de gênero que se realizava no início da cátedra feminista na Pós-Graduação em Ciências da Religião da UMESP, nas pesquisas e debates do núcleo de estudos da mulher na américa latina (NETMAL) e posteriormente no início da Revista Mandrágora -, a categoria era apresentada pela autora em articulação com a raça e 
a classe. Nos estudos de Joan Scott, fica explícito que é fundamental articular gênero com a classe e a raça, levando-se em consideração que as desigualdades de poder estão organizadas segundo, no mínimo, estes três eixos. Muito embora não se possa afirmar uma paridade entre estes três termos em sua aplicabilidade analítica ou aos processos estruturais, essa articulação é necessária e imprescindível. Tanto porque os acontecimentos percebidos por meio das relações sociais de poder convertem-se em uma chave de leitura que capta a multiplicidade de relações que se entrecruzam e se entre-determinam entre os grupos sociais, quanto pelo fato de que a corporeidade branca ou negra, por exemplo, não vivencia essas lutas da mesma maneira devido ao racismo estrutural em nossa sociedade.

Admitir a perspectiva de que falar em relações sociais é falar de relações de poder, faz aflorar a realidade da existência de grupos sociais em confronto e outros em aliança. A própria condição de subordinação está acompanhada de movimentos de resistência e apropriação destes espaços. No procedimento analítico de gênero e interseccionalidade, o poder não é tido como uma instância absoluta e estática, mas como um conjunto de forças que se movem entre os diversos sujeitos sociais podendo manifestar mudanças na cultura hegemônica. As distintas parcelas de poder vividas e assumidas pelos grupos sociais apresentam um jogo de poder dinâmico, no qual cada grupo social joga com suas parcelas de poder, ora fazendo alianças, ora rupturas, ora convergindo em um movimento histórico maior capaz de gerar mudanças na realidade.

As relações sociais de poder são o foco principal das análises de gênero, raça e classe. Nesse sentido, a perspectiva de Michel Foucault (2000) tem sido apreciada e apropriada em muitas reflexões, por s considerar que o poder se apresenta como constelações dispersas em parcelas, que são apropriadas diferentemente pelos grupos sociais, em contraposição a uma visão de poder como bloco homogêneo e único por parte das esferas dominantes. Nesse sentido, no lugar em que há poder, certamente haverá resistência, porque o processo de desigualdade de poder não presume o total esmagamento das pessoas ou grupos sociais, mas abre a possibilidade de sair da vitimização e encontrar os movimentos de resistência que existem na sociedade e provocam mudanças. 
O que a regulação normativa faz é dar uma forma, direção e propósito à conduta e à prática humanas; guiar nossas ações físicas conforme certos propósitos, fins e intenções; tomar nossas ações inteligíveis para os outros, previsíveis, regulares; criar um mundo ordenado no qual cada ação está inscrita nos significados e valores de uma cultura comum a todos. Naturalmente, na regulação normativa, com frequência, e sempre no fim, há ruptura - de outra forma, não haveria qualquer mudança, e o mundo repetiria a si mesmo simples e infinitamente (Stuart HALL, 1997, p. 42)

Nesse sentido, as reflexões a partir da categoria gênero permitem analisar as relações de poder entre os diversos grupos sociais, bem como os jogos de poder inerentes a estas relações sociais, nos quais se evidenciam os movimentos de resistência. Portanto, a proposição analítica da interseccionalidade que não apenas maneja a categoria gênero permite que o racismo estrutural, que atinge as mulheres negras, seja percebido e enfrentado e se desdobre em políticas públicas que as visibilizem, segundo os estudos de Carla Akotirene (2019).

Ao afirmar a interseccionalidade em conjunto com o referencial gênero busca-se demarcar que múltiplas são as experiências atravessadas por mais de um marcador social como raça, classe, geração, território imprimindo à corporeidade identidades distintas e, consequentemente, assimetrias diversas na experiência humana, segundo a compreensão de Carla Akotirene, para quem o enfrentamento das estruturas sociais só será possível efetivamente se assumirmos o cruzamento destes marcadores.

De pronto, a interseccionalidade sugere que raça traga subsídios de classe-gênero e esteja em um patamar de igualdade analítica. Ora, o androcentrismo da ciência moderna imputou às fêmeas o lugar social das mulheres, descritas como machos castrados, estereotipadas de fracas, mães compulsórias, assim como os pretos caracterizados de não humanos, macacos engaiolados pelo racismo epistêmico. Pretas e pretos são pretas e pretos em qualquer lugar do mundo. Na profusão de identidades viajantes, contingentes, fluidas, a cor da pele não se desarticula da identidade preta, [...] A interseccionalidade permite às feministas criticidade política a fim de compreenderem a fluidez das identidades subalternas impostas a preconceitos, subordinações 
de gênero, de classe e raça e às opressões estruturantes da matriz colonial moderna da qual saem. (Carla AKOTIRENE, 2019, p. 23 e 24)

Kimberlé Crenshaw (2002), por sua vez, ao sistematizar a compreensão de interseccionalidade, pondera que a identificação das injustiças sofridas pelas mulheres, por serem desdobramentos de uma opressão maior sofrida também por alguns homens, tem muita dificuldade em ser percebida como injustiça e assimetria de gênero e raça.

A universalização do homem, este branco, europeu, rico, cristão em detrimento da mulher e demais homens, não nos permite perceber as tramas e urdiduras dos jogos de poder que perpassam classes, gêneros, raças, as quais historicamente encontraram teorias pretendidas como "ciências absolutas" para justificarem o lugar definido para a corporeidade, esta que precisa estar sob controle para não alterar as forças no jogo de poder. A despeito de haver uma relação de poder que revela desigualdades, é fundamental perceber que o poder exercido nas relações, ainda que dominante, não é absoluto; há movimentos de resistências que movem a história das relações humanas, trazendo mudanças.

Avanços foram possíveis com a incorporação da categoria gênero nos estudos acadêmicos que contribuíram para a desconstrução de uma ciência e um conhecimento concebido como universal, no entanto, é preciso reconhecer que o enfrentamento ao racismo estrutural ainda precisa ser fortemente encarado nos estudos das relações sociais de poder. A tendência a fazer este debate sucumbir, ao afirmar gênero, é apenas uma demonstração do quanto a sociedade capitalista se vale desse processo de produção de subjetividade, que inculca um imaginário negativo e inferiorizador em relação a@s negr@s, imaginário este encoberto pela falácia da democracia racial no país.

Enfrentar essa intrincada relação de poder requer que se traga à luz o privilégio da branquitude, que impede que muitas pessoas sensíveis às questões de gênero tenham a mesma sensibilidade para perceber a gama de discriminações e subordinações que o marcador social racial implica. O racismo que estrutura a sociedade brasileira tem alicerces profundos e se fundou na ideia de raça, concebida no ocidente como superioridade d@s branc@s sobre xs demais, levando a um processo de invisibilidade da ideia de raça por parte das pessoas brancas, que 
não se pensam como raça, mas como ser humano universal.

Ao processo de silenciamento das pessoas brancas sobre o racismo ou a negação de que ele exista, Maria Aparecida Bento (2002), em sua tese doutoral, o chama de "pacto narcísico entre brancos", trazendo à tona a falta de sensibilidade das pessoas brancas para com o grupo social que não é o seu. No interior desse pacto não verbalizado, que fortalece as relações entre iguais, se manifesta a branquitude de que trata Cida Bento e é acompanhada por Lia Schucman (2014), apontando a branquitude como um lugar confortável em que as pessoas brancas falam d@soutr@s com um olho e uma lente que não olham a si mesmas, porque se sentem como padrão de humanidade, a partir do qual a@s outr@s é que são @s diferentes. Nesse sentido, a reflexão de Kabengele Munanga é uma conclamação necessária e urgente.

Cremos que a educação é capaz de oferecer tanto aos jovens como aos adultos a possibilidade de questionar e desconstruir os mitos de superioridade e inferioridade entre grupos humanos que foram introjetados neles pela cultura racista na qual foram socializados. Apesar da complexidade da luta contra o racismo, que consequentemente exige várias frentes de batalhas, não temos dúvida de que a transformação de nossas cabeças de professores é uma tarefa preliminar importantíssima. Essa transformação fará de nós os verdadeiros educadores, capazes de contribuir no processo de construção da democracia brasileira, que não poderá ser plenamente cumprida enquanto perdurar a destruição das individualidades históricas e culturais das populações que formaram a matriz plural do povo e da sociedade Brasileira (Kabengele MUNANGA, 2005, p. 16).

A estas palavras de mestres da sabedoria ancestral, desejo unir as de Paulo Freire que, muito cedo em sua vida de educador, já identificava a ofensa verbal sofrida pelos negros e negras, dada às normas do discurso da classe branca. Em suas palavras: "a violência verbal contra os negros alertou minha consciência a um nível que eu comecei não apenas a compreender que a sociedade brasileira era profundamente racista e injusta, mas essa injustiça provocou em mim um senso de revolta e desgosto" (Paulo Freire, 2001, p. 260). 
Os seus textos passaram a nomear as mulheres e homens, assim como a enfrentar a violência da linguagem racista. Ele reconheceu sua revisão no âmbito da linguagem, a partir do questionamento feito pelas feministas de que sua obra era sexista, apesar de preconizar a libertação das opressões. Ele admitiu que, durante um tempo em sua vida, se justificava dizendo que, ao usar a expressão "homem" entendia que a mulher necessariamente já estava incluída. No entanto, ele mesmo foi percebendo que estas tentativas eram puramente ideológicas e ocultavam uma linguagem sexista e androcêntrica que pretendia fazer uma inclusão, o que não era possível se o contrário fosse pronunciado.

A linguagem como sistema de significação é, ela própria, expressão da cultura e das relações sociais de um determinado momento histórico ou como expressou Stuart Hall

trata-se aqui da relação entre a linguagem e o que podemos denominar 'realidade'[...] o significado surge não das coisas em si - a "realidade" - mas a partir dos jogos da linguagem e dos sistemas de classificação nos quais as coisas são inseridas. O que consideramos fatos naturais são, portanto, também fenômenos discursivos (1997, p. 28,29).

E nesse ponto, nos encontramos novamente com a conjunção da categoria gênero e interseccionalidade.

\section{CAMINHOS E DESCAMINHOS PROVOCADOS PELA RELIGIÃO E RES- GATADOS PELA ÉTICA DA ALTERIDADE}

Em um tempo foi possível pensar a religião como elemento importante na constituição da pessoa, em outros como forma de dominação de populações pela força das lideranças religiosas e políticas mediadas pelos interesses econômicos, em outros como o cotidiano vivido pelas pessoas em sua busca de uma espiritualidade que fizesse sentido.

A possibilidade de pensar a espiritualidade me leva ao encontro da gratuidade aprendida das minhas avós, que se abriam para@outr@ sem pedir nada em troca, por um amor gratuito desejavam o bem, tinham palavras de sabedoria, de compaixão e sabiam acolher aquel@s 
que pensavam diferente, embora nem sempre concordassem. Entre os aprendizados que me marcaram na tradição cristã e familiar está a teologia da gratuidade, presente no primeiro testamento, em contraposição a uma teologia da retribuição, tão combatida pela profecia. $\mathrm{Na}$ teologia da retribuição, que exigia sacrifício para engordar os cofres do templo e dos sacerdotes, estava a marca da religião da troca, de uma divindade que só se acalmava diante da extorsão feita axs mais marginalizados daquela sociedade. $O$ segundo testamento aponta para um Jesus que caminha cotidianamente junto a@s empobrecid@s, a@s enferm@s, às mulheres, a@s marginalizad@s e expulsa do templo a@s que vendem a aproximação com a benção divina em troca do alto custo das oferendas. Hoje em dia, vejo muito dessa religião da retribuição, da prosperidade, fazendo dos lugares de culto um grande comércio de produtos que se apresentam como mediadores entre as pessoas e o mistério que nos transcende.

Por isso, faço coro com Conceição Evaristo, "quando meus pés abrandarem na marcha, por favor, não me forcem. Caminhar para quê? Deixem-me quedar, deixem-me quieta, na aparente inércia. Nem todo viandante anda estradas, há mundos submersos, que só o silêncio da poesia penetra" (2008, p.124). Os momentos do corpo em silêncio, sem pressa para ter algo a dizer ou a certeza de um caminho a seguir, são fundamentais para o encontro com uma espiritualidade que faça sentido.

A espiritualidade que desejo é esta que me conecta com o Outr@, a outra pessoa que diante de mim me provoca, me interpela, me desafia a me construir a partir da relação eu-outr@. Em uma experiência de profunda abertura para o rosto do outr@, que me convoca a viver relações sociais de poder, sem que estas sejam de dominação ou subordinação. O convite a olhar para o Outr@, é um chamado à alteridade que pode e precisa nos des-instalar.

E alteridade é aqui afirmada com base na concepção de desafio à responsabilidade pelo Outro diferente de mim e que me interpela, me demanda uma res-posta, uma res-ponsabilidade, um res-peito, segundo Lévinas (1988). Nesta acepção de alteridade, o rosto do Outr@, com seu olhar, inaugura a linguagem que desafia ao deslocamento de nós mesm@s e à abertura para sairmos da pretensão de olharmos a nós 
mesm@s como única referência. O movimento disparado pelo face-a-face nos possibilita sair das redes de dominação em que as diversidades não cabem. O mesmo autor afirma que:

O rosto onde se apresenta o Outro - absolutamente outro - não nega o Mesmo, não o violenta como a opinião [...]. Essa apresentação é a não-violência por excelência, porque em vez de ferir a minha liberdade, chama-a à responsabilidade e implanta-a. Não violência, ela mantém, no entanto, a pluralidade do Mesmo e do Outro. (Emmanuel LÉVINAS, 1988, p. 181).

O rosto do Outr@, em seu olhar, como uma convocação que interpela, que insiste na reciprocidade, evidenciou o que Lévinas propôs ao afirmar que o olhar fala, em suas palavras "o rosto fala", considerando sua perspectiva de que "o rosto e o discurso estão, portanto, intimamente ligados [...] o rosto fala porque é ele que torna possível e começa todo discurso" (Emmanuel LÉVINAS, 1982, p. 79) e, nesse processo, inicia-se uma relação de responsabilização entre o Eu e o Outr@, da qual não se pode apartar.

Esse processo de encontro, que me responsabiliza frente ao Outr@ e gera mudanças, eu chamo de "espiritualidade com sentido", pois me possibilita rever o pacto narcísico entre@s @ranc@s, me desinstala das verdades absolutas que controlam a corporeidade a favor de um mercado antropofágico e desconstrói uma ciência branca e masculina, responsável por muito do racismo, do sexismo e da lgbtfobia entre outras formas de discriminação presentes. A aproximação do Outr@ diferente me permite entender a profundidade do clamor para que a interseccionalidade seja articulada com os ganhos históricos que o referencial de gênero logrou nas últimas décadas, tanto como categoria de análise, quanto como esclarecedora das relações sociais de poder vividas no cotidiano.

A ética da alteridade, que se depreende desse olhar atento a@ outr@em abertura para que este me constitua como pessoa, se apresenta como caminho de transformação das assimetrias. @ Outr@ diferente, que não sou eu mesmo, me modifica na relação, e me permite estar na contramão da lógica da sociedade capitalista de mercado que 
produz uma subjetividade de exclusão d@ Outr@, ao apresenta-l@ como meu adversário e concorrente. Querer estar e ser no mundo, na mais profunda abertura aprendente diante do Outr@ diferente, me possibilita o encontro com a gratuidade das relações e, portanto, com uma espiritualidade que faça sentido.

É importante perceber que esta responsabilização de minha parte em relação ao Outro não faz desaparecer a singularidade do Eu. Segundo Emmanuel Lévinas, “[...] trata-se de uma resposta que nenhum outro pode dar em meu lugar. Ao responder ao apelo do outro me afirmo como sujeito único e insubstituível. Eu, não intercambiável, sou apenas na medida em que sou responsável” (1982, p.84). Sendo assim, há uma relação mútua de acolhida e de resposta, na qual a diferença constitui a cada um e cada uma como ser singular, interpelando a quem está na relação, a não ignorar e não subjugar @ Outr@ e sim responsabilizar-se pela construção de relações em que caibam tod@s.

\section{CONSIDERAÇÕES FINAIS}

Em busca de celebrar as conquistas e desejar vida longa à Mandrágora, ao Núcleo de Estudos, à cátedra feminista da Pós-Graduação em Ciências da Religião fiz o percurso de dizer do referencial teórico de gênero, aprendido neste lugar, e este interseccionado à raça, à classe e a outros marcadores sociais, como uma pauta não apenas acadêmica, mas fundante em minha relação com @ Outr@. Essa compreensão de que as relações sociais são sempre relações de poder e de que onde há poder há resistência, me levou a encontrar na ética da alteridade uma saída aos desencantos com a religião e a uma aproximação com uma espiritualidade da gratuidade.

Desejo que nossa abertura, a@ Outr@ diferente, nos fortaleça para a luta, mas também torne a vida mais leve, para que possamos desfrutar gratuitamente da companhia daquel@ que não sou eu e, portanto, me salva dos pactos narcísicos que reverberam exclusão e marginalização. Oxalá que essa prosa tenha sua continuidade em outros momentos! 


\section{REFERÊNCIAS BIBLIOGRÁFICAS}

AKOTIRENE, Carla. Interseccionalidade. São Paulo: Sueli Carneiro; Pólen. Feminismos Plurais, coordenação Djamila Ribeiro, 2019.

BENTO, Maria Aparecida S. Pactos narcísicos no racismo: branquitude e poder nas organizações empresariais e no poder público. Tese de Doutorado, Instituto de Psicologia da Universidade de São Paulo, São Paulo, 2002.

BUTLER, Judith. Violência, Luto, Política. IN: BAPTISTA, Maria Manuel (org.). Género e Performance. Textos Essenciais 1, Grácio Editor, Coimbra, Portugal. 2018, (p. 21-51).

CRENSHAW, kimberlé. Documento para o encontro de especialistas em aspectos da discriminação racial relativos ao gênero. Revista de Estudos Feministas. vol.10, n.1, pp. 171-188, Florianópolis, SC, Jan. 2002.

EVARISTO, Conceição. Poemas da recordação e outros movimentos. Belo Horizonte: Nandyala, 2008.

FOUCAULT, Michel. Microfísica do poder. 15.ed. Rio de Janeiro: Graal, 2000.

FREIRE, Ana Maria Araújo (org.). Pedagogia dos Sonhos possíveis: Paulo Freire. São Paulo, UNESP, 2001.

GEBARA, Ivone. Teologia ecofeminista: ensaio para repensar o conhecimento e a religião. São Paulo: Olho d'água, 1997.

HALL, Stuart. A centralidade da cultura: notas sobre as revoluções culturais do nosso tempo. Educação \& Realidade. Porto Alegre, v.22, n.2, p.15-46, jul./dez. 1997.

HALL, Stuart. Da diáspora: identidades e mediações culturais. Belo Horizonte: Ed. da UFMG, 2003.

HALL, Stuart. A identidade cultural na pós-modernidade. $11^{\mathrm{a}}$ ed. Rio de Janeiro: DP\&A, 2006.

MORIN, Edgar. A cabeça bem-feita: repensar a reforma, reformar o pensamento. Rio de Janeiro: Bertrand Brasil, 2000.

LÉVINAS, Emmanuel. O humanismo do outro homem. Petrópolis, RJ, Vozes, 2009.

LÉVINAS, Emmanuel. Totalidade e infinito. Lisboa, Portugal, Edições 70, 1988.

LÉVINAS. Emmanuel. Ética e infinito. Portugal, Lisboa, Edições 70, 1982.

LOURO, Guacira Lopes. Gênero, sexualidade e educação: uma perspectiva pós-estruturalista. Petrópolis, Rio de Janeiro, Vozes, 1997.

MUNANGA, Kabengele. Apresentação. In: MUNANGA, Kabengele (org.). Superando o Racismo na escola. $2^{\text {a }}$ edição revisada. Brasília: Ministério da Educação, Secretaria de Educação Continuada, Alfabetização e Diversidade, 2005.

PRIGOGINE, Ilya. O fim das certezas. Tempo, caos e as leis da natureza. São Paulo: EDUSP, 1996. 
SCHUCMAN, Lia V. Sim, nós somos racistas: estudo psicossocial da branquitude paulistana. Psicologia \& Sociedade, 26 (1), abril de 2014, p. 83-94.

SCOTT, J. W. Gênero: uma categoria útil de análise histórica. Educação \& Realidade. Porto Alegre, v.20, n.2, p.71-99, jul./dez. 1995.

Submetido em: 15-9-2021

Aceito em: 18-11-2021 